\title{
Postsynaptic Modifications in Long-Term Facilitation in Aplysia: Upregulation of Excitatory Amino Acid Receptors
}

\author{
Louis-Éric Trudeau and Vincent F. Castellucci \\ Laboratoire de neurobiologie et comportement, Institut de Recherches Cliniques de Montréal and Centre de Recherches \\ en Sciences Neurologiques, Département de physiologie, Université de Montréal, Canada
}

\begin{abstract}
Long-term sensitization of the gill and siphon withdrawal in Aplysia is accompanied by facilitation of sensorimotor synaptlc connections that depends on new protein synthesis. This phenomenon has been previously shown to involve presynaptic growth. At the postsynaptic level, a reorganization should occur to parallel the formation of new synaptic contacts. We show here that $24 \mathrm{hr}$ following an application of 5-HT, which produces long-term synaptic facilitation (LTF), the response of the motoneuron to an excitatory amino acid agonist of the synaptic receptors is increased. General inhibition of protein synthesis with anisomycin blocks this enhancement. Inhibition of protein synthesis limited to the postsynaptic neuron by intracellular injection of gelonin, a ribosome-inactivating toxin, also blocks the increase in the response to the agonist but fails to block $24 \mathrm{hr}$ LTF. These results are compatible with a model of LTF that involves coordinate pre- and postsynaptic changes. The latter may include an upregulation of functional postsynaptic receptors. These may not be initially required for LTF measured at a $\mathbf{2 4} \mathrm{hr}$ time point, but could become necessary for later stages of LTF. An increase in the number of functional postsynaptic receptors in a reserve pool may also prime the postsynaptic neuron for subsequent learning-associated plasticity.
\end{abstract}

[Key words: Aplysia, excitatory amino acid, memory, postsynaptic, receptor, synaptic plasticity]

It has been demonstrated that synaptic transmission from sensory neurons of the siphon to motoneurons of the gill or siphon in the abdominal ganglion of Aplysia californica is increased in animals that received long-term sensitization training, a model system for the study of long-term memory (Pinsker et al., 1973; Frost et al., 1985). Using a semiintact preparation, it has also been found that the induction of long-term sensitization is dependent on new protein synthesis (Castellucci et al., 1989), a characteristic of long-term memory in invertebrates such as Aplysia and Hermissenda (Crow and Forrester, 1990; but see

\footnotetext{
Received May 20, 1994; revised July 28, 1994; accepted Aug. 3, 1994.

We thank T. Ouimet and Drs. M. Klein and W. Sossin for comments on earlier versions of the manuscript, and $\mathrm{C}$. Lemire for secretarial assistance. This work was funded in part by Grant MT-12092 from the Medical Research Council of Canada and by the Richard and Edith Strauss Canada Foundation. L.-E. Trudeau is the recipient of a "1967" graduate fellowship from the Conseil de Recherches en Sciences Naturelles et en Génie du Canada

Correspondence should be addressed to Dr. Vincent François Castellucci, Laboratoire de neurobiologie et comportement, Institut de Recherches Cliniques de Montréal, 110, avenue des Pins ouest, Montréal, Québec, H2W 1R7, Canada.

Copyright (C) 1995 Society for Neuroscience $0270-6474 / 95 / 151275-10 \$ 05.00 / 0$
}

Wittstock et al., 1993) as well as in vertebrates (Flexner et al., 1963; Agranoff and Klinger, 1964; Barondes and Cohen, 1967, 1968; Horn et al., 1979; Grecksch and Matthies, 1980; Krug et al., 1984; Takamatsu and Tsukada, 1985; Deadwyler et al., 1987).

In Aplysia, studies using synapses formed between isolated sensory and motor neurons in primary culture have also shown that a treatment that mimics long-term sensitization training (repeated applications of the modulatory transmitter 5-HT) can produce an increase in EPSP amplitude lasting more than 24 hr. This effect is also blocked by inhibitors of translation and transcription if they are applied during or within the first hour following the beginning of the 5-HT treatment (Montarolo et al., 1986). It has been hypothesized that long-term synaptic facilitation (LTF) is induced presynaptically by a protein kinase A (PKA)-dependent activation of cAMP response element binding (CREB) transcription factors, leading to modifications of the transcription of a variety of genes such as other transcription factors, cell adhesion molecules, or structural proteins (Dale et al., 1987, 1988; Greenberg et al., 1987; Scholz and Byrne, 1987, 1988; Castellucci et al., 1988; Schacher et al., 1988; Barzilai et al., 1989; Eskin et al., 1989; Sweatt and Kandel, 1989; Dash et al., 1990; Noel et al., 1991; Bergold et al., 1992; Kennedy et al., 1992; Kuhl et al., 1992; Mayford et al., 1992; Hu et al., 1993; Kaang et al., 1993; Noel et al., 1993; Schacher et al., 1993; Alberini et al., 1994). LTF of the synaptic connections between sensory and motor neurons in the abdominal ganglion of Aplysia has also been examined at the ultrastructural level. It has becn proposed that a major mechanism of long-term sensitization is the growth of new sites of transmitter release from sensory neurons onto motoneurons, although to this date there has been no direct demonstration that the presynaptic growth is both necessary and sufficient for the expression of LTF (Bailey and Chen, 1983, 1988a,b, 1989; Glanzman et al., 1990; Nazif et al., 1991; Bailey et al., 1992; Schacher et al., 1993).

Data are lacking about possible postsynaptic modifications that could accompany LTF. For example, if the growth of new synaptic contacts is, indeed, necessary for $24 \mathrm{~h} \mathrm{LTF}$, it is not clear what kind of reorganization is taking place at the postsynaptic level to accommodate this growth. The question also arises as to whether protein synthesis is necessary only presynaptically, or both pre- and postsynaptically for the expression of LTF. If it is important only presynaptically, one possibility is that previously functional but nonsynaptic receptors are recruited to the new sites of contact on the postsynaptic neuron. Another possibility is that LTF is accompanied by a posttranslational activation of previously existing but nonfunctional receptors. If 
new protein synthesis is also necessary in the postsynaptic cell, this could implicate an increased synthesis of synaptic receptors which are then targeted to the new synaptic sites. A combination of these mechanisms is also possible.

Postsynaptic reorganizations in association with or in response to presynaptic growth have not been frequently reported. One model system is the development of the neuromuscular junction. There it is known that an interaction between ingrowing nerve terminals and muscle is involved in the clustering and metabolic stabilization of junctional receptors as well as in the induction of a localized expression of synaptic receptors (Broadie and Bates 1993; Caroni et al., 1993; Froehner, 1993). More in the context of learning-related plasticity, it is interesting to note that it has been recently found that during formation of imprinting in ducklings, the expression of a kainate-binding protein (which may be an excitatory amino acid receptor subunit) is apparently increased (Kimura et al., 1993). Finally, in Aplysia, Wu and Schacher (1994) have recently found that longterm heterosynaptic inhibition produced by the neuropeptide FMRFamide may have a postsynaptic component. It is associated with an increase in the endocytosis of a cell-adhesion molecule in the postsynaptic cell, although the relationship of this effect to the presynaptic changes in transmitter release that have been previously described are not clear (Montarolo et al., 1988; Schacher and Montarolo, 1991).

An exploration of putative postsynaptic mechanisms of modulation involved in LTF in Aplysia has recently become possible following the demonstration that the receptors that are present at sensorimotor synapses belong to the excitatory amino acid (EAA) receptor family (Dale and Kandel, 1993; Trudeau and Castellucci, 1993a). The availability of various agonists and antagonists has allowed us to investigate, in the present study, whether treatments that produce LTF also produce a long-term change in the sensitivity of motoneurons to an agonist of the synaptic receptors.

\section{Materials and Methods}

Animals. Aplysia californica (100-300 gm) were obtained from Marine Specimens (Pacific Palisades, CA). All experiments were performed on isolated abdominal ganglia dissected from the animal following anesthesia with an injection of $385 \mathrm{~mm} \mathrm{MgCl}$ corresponding approximately to half of the animal's volume. The ganglia were pinned to the bottom of a Sylgard-coated petri dish containing a 1:1 mixture of artificial sea water (ASW) and $385 \mathrm{mM} \mathrm{MgCl}_{2}$, and the connective tissue covering the left side of the ganglia was removed using fine forceps. Following dissection, the preparation was perfused for approximately $1 \mathrm{hr}$ with 2:1 ASW (see below) before beginning experiments. For experiments that required retesting preparations following a $24 \mathrm{hr}$ interval, the ganglia were incubated at $17^{\circ} \mathrm{C}$ in $\mathrm{L} 15$ culture medium (Gibco; Grand Island, NY) with glutamine, antibiotics, and salts adjusted to ASW concentrations. The culture medium was washed off for 30 to $60 \mathrm{~min}$ and replaced with 2:1 ASW before preparations were retested the next day.

Electrophysiology and data acquisition. Standard techniques were used for intracellular recordings. Elcetrodes contained $2 \mathrm{M} \mathrm{KAc}$ for recordings from motoneuron L7. They were beveled to a resistance of 7-12 M 2 . Electrodes contained $1.5 \mathrm{M} \mathrm{KCl}$ for recordings from sensory neurons of the LE or rLE clusters (Dubuc and Castellucci, 1991). They were beveled to a resistance of 15-20 M 2 . Presynaptic membrane potential was recorded through an Axoprobe $1 \mathrm{~A}$ amplifier (Axon instruments, Foster City, CA). Postsynaptic potential or current was recorded with an Axoclamp 2 A amplifier (Axon instruments). Voltage clamp experiments were performed in the two-electrode mode. For the measurement of agonist-induced currents, motoneuron L7 was voltage clamped at -90 $\mathrm{mV}$ with two KAc electrodes in the presence of a 2:1 ASW medium to diminish spontaneous activity in the ganglion and prevent excessive firing and bursting of other neurons in the ganglion during application of the excitatory amino acid receptor agonist (see Trudeau and Castellucci, 1992). A $200 \mu \mathrm{l}$ volume of $3.5 \mathrm{~mm}$ HCA (homocysteic acid) was perfused (at $400 \mu \mathrm{l} / \mathrm{min}$ ) over the left side of the abdominal ganglion, thereby exposing the soma of $\mathrm{L} 7$ and nearby neuropil region (where synaptic contacts onto L7 are made) to the HCA solution. Both inflow and outflow pipes consisted of $300 \mu \mathrm{m}$ inner diameter polyethylene tubing positioned across the ganglion. Fast green dye $(0.05 \%)$ was included in the HCA solution to visualize the flow. We estimate a dilution factor of approximately three in the concentration of agonist that reaches the cell.

Data was acquired in parallel on the hard disk of a 486 computer and on VHS tape. Computer acquisition and analysis of the data was performed with the pclaMp software ( $\Lambda$ xon instruments). A modified version of CLAMPEX was used to measure EPSPs evoked by action potentials in sensory neurons (provided by Dr. M. V. Storozhuk, Meharry Medical College, Nashville, TN). Data in the text are expressed as mean \pm SEM. Statistical comparisons were performed using either $t$ tests or ANOVAs along with post hoc tests, where appropriate.

Determination of methionine incorporation. Protein synthesis was evaluated by measuring the incorporation of ${ }^{35} \mathrm{~S}$-methionine into newly synthesized proteins. To evaluate the efficacy of the inhibitors used in our experiments, large left-upper-quadrant (LUQ) neurons of the abdominal ganglion were used. Three conditions were used: (1) control untreated ganglion, (2) ganglion pretreated for $45 \mathrm{~min}$ with the protein synthesis inhibitor anisomycin $(20 \mu \mathrm{M})$, and (3) ganglion in which four large LUQ neurons were intracellularly injected with the plant-derived ribosome-inactivating glycoprotein gelonin $(25 \mu \mathrm{M}$ in the injection electrode; final concentration in the cell body estimated at approximately $250 \mathrm{nM}$ by visually monitoring the injected volume through the use of fast green dye, $0.5 \%$, included in the injection buffer). The gelonin (Stripe et al., 1980; Falasca et al., 1982; Singh et al., 1989) was kindly provided and purified by P. Apostolakos and Dr. M. R. Sairam (Institut de Recherches Cliniques de Montréal) and diluted in $100 \mathrm{mM} \mathrm{NaCl}, 10 \mathrm{~mm}$ Tris. A $60 \mathrm{~min}$ incubation period was used in the gelonin condition before exposure to ${ }^{35} \mathrm{~S}$-methionine. The ganglia were then incubated in the presence of 2:1 ASW containing $200 \mu \mathrm{Ci}{ }^{35}$ S-methionine (DuPont Canada; Mississauga, Ont.) for $6 \mathrm{hr}$. After washout of the medium, four LUQ neuronal cell bodies were dissected from the ganglia in the presence of a cold 1:1 mixture of glycerol and $2 \mathrm{M} \mathrm{NaCl}$. Methods were as in Schwartz and Swanson (1987), except that ganglia were digested for 30 min in bacterial protease (type IX;10 $\mathrm{mg} / \mathrm{ml}$ ) before the initial treatments to facilitate later dissection of individual cells. Radioactivity incorporated in TCA-precipitable proteins was then counted for each pool of four cells. This experiment was performed three times. The anisomycin treatment was found to block protein synthesis in these neurons by $96.3 \pm 1.9 \%(n=3)$ relative to the control condition. The gelonin injection was also found to be effective, blocking incorporation by $69.9 \pm 6.4 \%(n=3)$. The effectiveness of gelonin is probably underestimated in these experiments because it is probable that some small (uninjected) neurons and glial cells remained attached to the large cell bodies isolated for radioactivity counting.

Drugs and media. 5-Hydroxytryptamine creatinine sulfate monohydrate $(5-\mathrm{HT})$ and genistein were obtained from ICN Biochemicals (Cleveland, $\mathrm{OH}$ ). 6-Cyano-7-nitroquinoxaline-2,3-dione (CNQX) and Rp-cAMPS triethylamine salt (Rp-cAMP) were from Research Biochemicals (Natick, MA). Protease (type IX), anisomycin, $d$-tubocurarine, 8-(4-chlorophenylthio)-cAMP sodium salt (cpt-cAMP), 3-isobutyl1 -methylxanthine (IBMX), and homocysteic acid were from Sigma (St. Louis, MO). Ethylenebis-(oxyethylenenitrilo)tetraacetic acid (EGTA) was from Fisher Scientific (Fair Lawn, NJ), and 1-(5-isoquinolinesulfonyl)2-methylpiperazine dihydrochloride (H-7) was from Seikagaku Kogyo Co. Ltd. (Tokyo, Japan). ASW consisted of (in mM) $460 \mathrm{NaCl}, 10 \mathrm{KCl}$, $11 \mathrm{CaCl}_{2}, 25 \mathrm{MgSO}_{4}, 30 \mathrm{MgCl}_{2}, 10 \mathrm{~N}$-2-hydroxyethylpiperazine- $N ;^{\prime}-2$ ethanesulfonic acid (HEPES) buffer, pH 7.6. The 2:1 ASW is a medium containing twice the normal concentration of $\mathrm{Mg}^{2+}$ and 1.25 times the normal concentration of $\mathrm{Ca}^{2+}$ and which is effective at decreasing neuronal excitability (Trudeau and Castellucci, 1992). It consisted of (in mм) $368 \mathrm{NaCl}, 8 \mathrm{KCl}, 13.8 \mathrm{CaCl}_{2}, 20 \mathrm{MgSO}_{4}, 101 \mathrm{MgCl}_{2}, 10 \mathrm{HEPES}$ buffer, pH 7.6.

\section{Results}

Characterization of the agonist response

The excitatory synaptic responses evoked in motoneurons of the GSW network by action potentials in sensory neurons and 
A

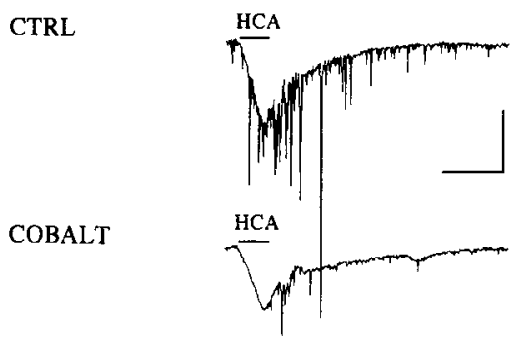

B

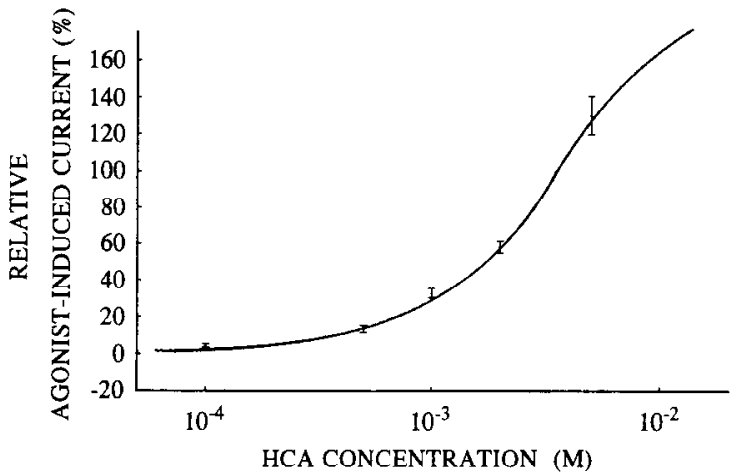

C

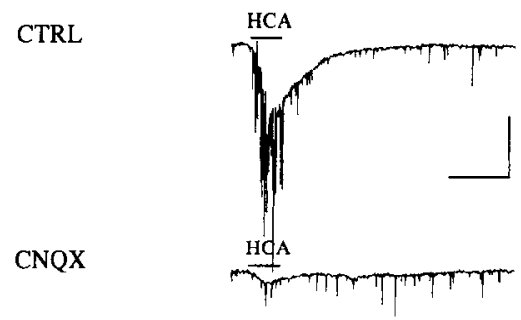

$\mathrm{D}$

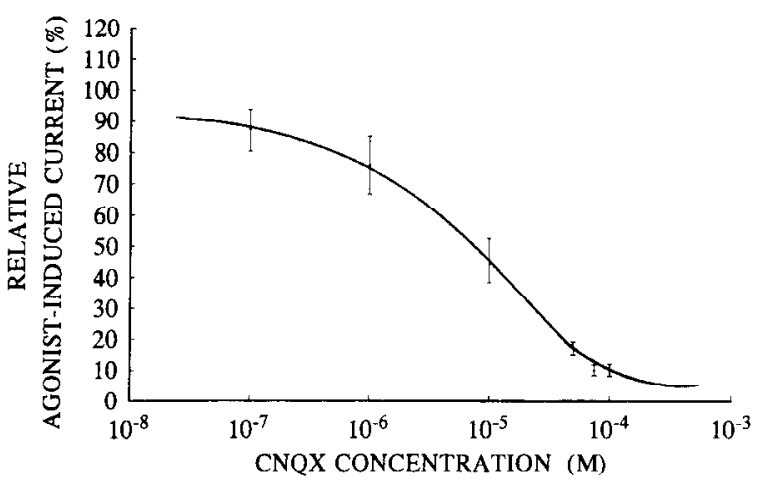

Figure 1. Current produced by homocysteic (HCA) acid in motoneuron L7. A, Application of HCA $(3.5 \mathrm{~mm}, 200 \mu \mathrm{l})$ by perfusion for 30 sec produces an inward current in motoneuron $\mathrm{L} 7$ voltage clamped at $-90 \mathrm{mV}$ (upper trace). Note the increase in the frequency of spontaneous synaptic events. In a medium containing $7 \mathrm{mM} \mathrm{CoCl}_{2}$, synaptic transmission is mostly blocked but the response to HCA persists (lower trace). Calibration: 9 nA, 1 min. $B$, Dose-response of the effect of $\mathrm{HCA}$ on motoneuron $\mathrm{L} 7$. The responses are expressed relative to the area of the current obtained using $3.5 \mathrm{~mm}$. Note that receptors activated are of low affinity (even though a dilution factor of up to three is possible because of the method of perfusion). $C$, Effect of the EAA receptor antagonist CNQX $(75 \mu \mathrm{M})$ on the current produced by $3.5 \mathrm{~mm}$ HCA. The lower trace was obtained 5 min following application of CNQX in the bath. The spontaneous synaptic currents that remain in the presence of CNQX excitatory interneurons are sensitive to blockade by the EAA receptor antagonists CNQX and DNQX (Trudeau and Castellucci, 1993a; Dale and Kandel, 1993). We have also previously shown that agonists effective at activating CNQX-sensitive receptors in the intact abdominal ganglion include homocysteic acid (HCA), kainic acid, and domoic acid (Trudeau and Castellucci, 1993a). Here we have used HCA-induced currents as an assay for functional EAA receptors present on motoneurons of the GSW network, although kainic acid or domoic acid could also have been used. We have specifically used identified motoneuron $\mathrm{L} 7$ because its soma is large $(>200 \mu \mathrm{m})$ and well suited for experiments involving repeated testing over a $24 \mathrm{hr}$ period.

The HCA application produces an inward current at a holding potential of $-90 \mathrm{mV}$, which is accompanied by an increase in spontaneous synaptic currents (Fig. $1 A$ ). As we have previously shown (Trudeau and Castellucci, 1993a), this current that produces a depolarization in motoneurons, is a direct response of the cell to the agonist, as it is unaffected (Fig. $1 A$ ) by the presence of $7 \mathrm{mM} \mathrm{CoCl}_{2}$ (replacing an equivalent concentration of $\mathrm{CaCl}_{2}$ ), a procedure that blocks synaptic transmission by approximately $80 \%$ under our conditions (results not shown). The mean change in the area of the current following $\mathrm{CoCl}_{2}$ was $-6.4 \% \pm 7.2 \%$ $\lceil n=5$; paired $t$ test, $t=0.3$, not significant (NS) . A doseresponse curve of the HCA-induced current is presented in Figure $1 B$. It illustrates that the receptors are of low affinity for the agonist. It was difticult to extend the dose-response to concentrations of agonist higher than $5 \mathrm{~mm}$ because it appears that at these concentrations other non-CNQX-sensitive receptors arc also activated (results not shown; see also Trudeau and Castellucci, 1993a).

As mentioned above, $\mathrm{HCA}$ is able to activate receptors which, like the synaptic receptors, are sensitive to CNQX. Figure $1 C$ shows the effect of $75 \mu \mathrm{M}$ CNQX on the HCA current. At this concentration, the response was blocked by $89.8 \% \pm 1.7 \%(n$ $=4 ; t=18.0, p<0.001)$. It is clear that at a concentration of $3.5 \mathrm{~mm}, \mathrm{HCA}$ is able to activate almost exclusively receptors that are susceptible to CNQX antagonism. A dose-response of the effect of CNQX on the HCA current was obtained (Fig. 1D). The concentration necessary to block $50 \%$ of the response was found to be between 5 and $10 \mu \mathrm{M}$.

Another characteristic shared by the synaptic receptors and the receptors activated by $\mathrm{HCA}$ is their susceptibility to protease digestion. We found that this procedure, which is commonly used to dissociate cells for primary culture, completely abolished the response to $\mathrm{HCA}$ (Fig. $2 A$ ). Likewise, the synaptic activation of motoneuron L7 in the intact abdominal ganglion by stimulation of sensory axons in the siphon nerve was almost completely blocked (Fig. $2 B$ ). Even stimulation intensities 10 times higher than used in the control period were ineffective at evoking bigger synaptic currents. These EAA receptors seem to be especially sensitive to this treatment because synaptic currents mediated by cholinergic receptors at other synapses in Aplysia were less affected by protease digestion. The cationic synaptic current evoked in neuron R 15 by stimulation of an axon in the

are of cholinergic nature. Calibration: $9 \mathrm{nA}, 1 \mathrm{~min} . D$, Dose-response of the effect of CNQX on the current evoked by $3.5 \mathrm{~mm} \mathrm{HCA}$. The currents are expressed relative to the initial controls of each experiments. The $\mathrm{EC}_{50}$ is between 5 and $10 \mu \mathrm{M}$. 


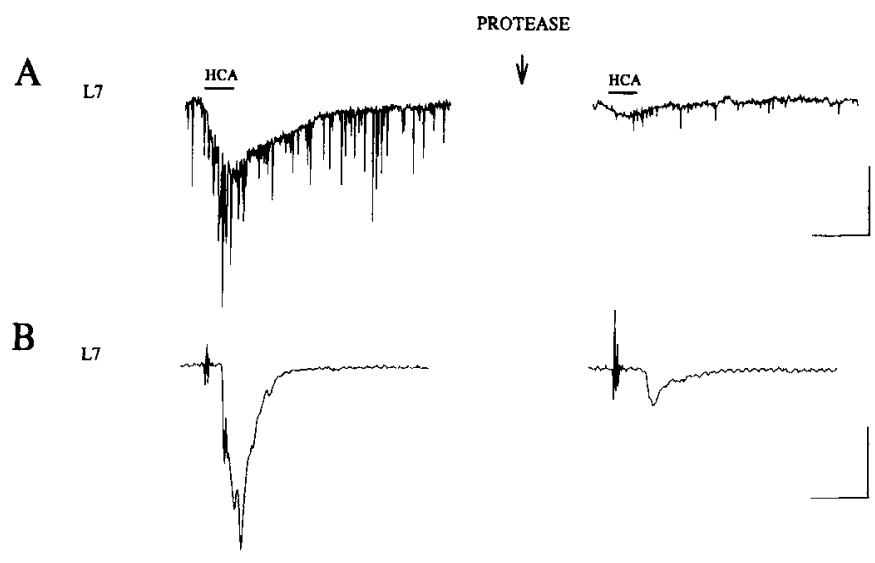

DAY 1

DAY 2

A

CTRL

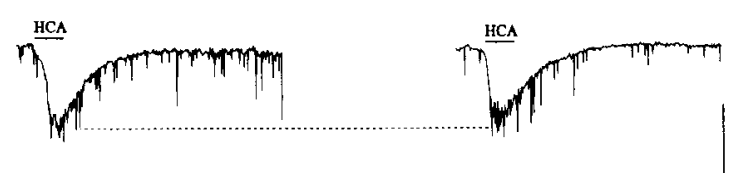

B

$5-\mathrm{HT}$

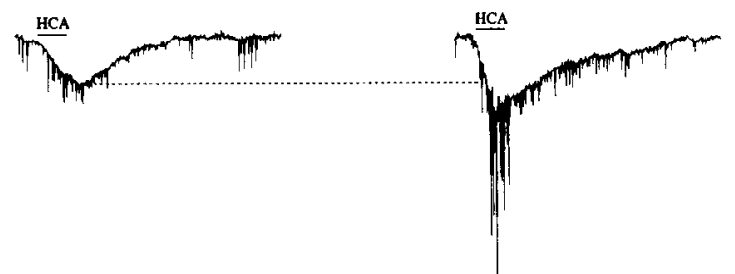

C
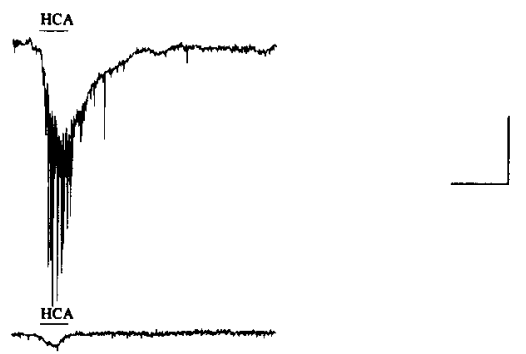

E ISOLATED SOMA

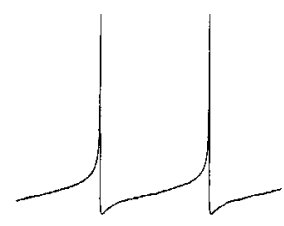

Figure 2. The receptors activated by $\mathrm{HCA}$ are sensitive to protease digestion and have a nonsomatic localization. $A$, Current evoked in voltage clamped motoneuron L7 by $3.5 \mathrm{~mm}$ HCA (left). Following digestion of the ganglion with bacterial protease (type IX; $10 \mathrm{mg} / \mathrm{ml}$, $60 \mathrm{~min}, 27^{\circ} \mathrm{C}$ ) the response is mostly abolished (right). A comparison of the HCA current in individual motoneurons before and after the digestion showed that the response was blocked by $91.2 \% \pm 3.7 \%(n=$ $6 ; t=3.9, p<0.02$ ). Calibration: $5 \mathrm{nA}, 1 \mathrm{~min}$. $B$, Compound synaptic current (holding, $-90 \mathrm{mV}$ ) evoked in neuron L7 by a brief stimulation $(3 \mathrm{msec}, 5 \mathrm{~V})$ of the siphon nerve (left). Protease digestion eliminates most of this current (right) (same neuron as in $A$ ). A mean decrease of $88.3 \% \pm 3.5 \%(n=4 ; t=3.4, p<0.05)$ was obtained. Calibration: 15 nA, $150 \mathrm{msec} . C$, Nonsomatic localization of the receptors activated by HCA. Current evoked by $3.5 \mathrm{~mm} \mathrm{HCA}$ in motoneuron $\mathrm{L} 7$ in the intact abdominal ganglion. Calibration: $8 \mathrm{nA}, 1 \mathrm{~min}$. $D$, Current evoked by HCA in the isolated soma of motoncuron L7 (same neuron as in C). For these experiments, the neuron was first voltage clamped in the intact abdominal ganglion and its HCA current measured. The electrodes were then withdrawn and the cell body was surgically separated from its processes through the use of a sharp-tipped forceps. The acutely isolated soma was then transferred to an uncoated petri dish and allowed to adhere to the plastic for $3 \mathrm{hr}$. Following this delay the soma was reimpaled with two electrodes and voltage clamped at $-90 \mathrm{mV}$, whereupon the HCA current was again measured. Same calibration as in $C$. $E$, Spontaneous action potentials recorded in the same neuron as in $C$ and $D$, showing that the isolated soma was in good condition. Calibration; $25 \mathrm{mV}, 600 \mathrm{msec}$.
D

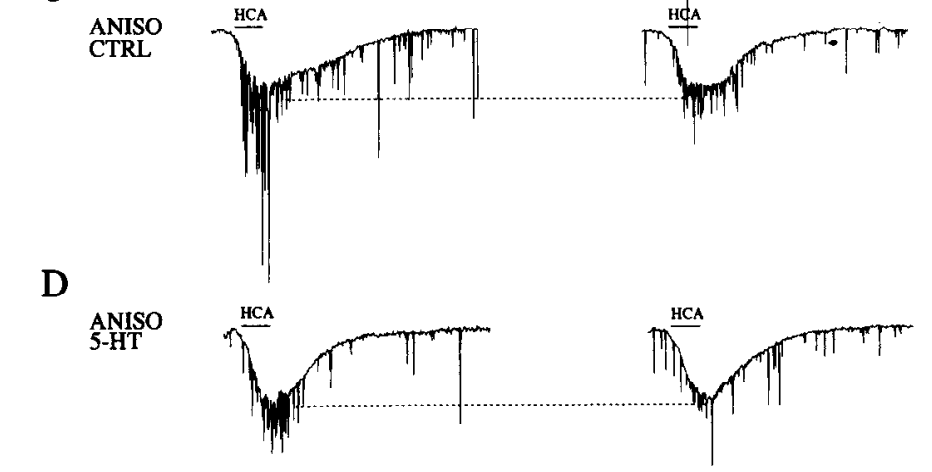

Figure 3. 5-HT induces a long-term enhancement of the HCA current that is dependent on new protein synthesis. $A$, Current evoked by 3.5 mм HCA $(200 \mu \mathrm{l})$ on 2 consecutive days (day 1, day 2$)$ in the same L7 motoneuron. The currents were obtained in the presence of the 2:1 ASW medium. In control (CTRL) experiments the area of the current is stable. over $24 \mathrm{hr}$. Calibration: $9 \mathrm{nA}, 1 \mathrm{~min}$ (same calibration in $B-D$ ). $B$, After measurement of the current evoked by HCA on day 1 (left), the electrodes were withdrawn from motoneuron $\mathrm{L} 7$ and the serotonin $(5-H T)$ was applied at $5 \mu \mathrm{M}$ for a continuous period of $60 \mathrm{~min}$, a procedure that has been previously shown to induce long-term changes in presynaptic sensory neurons (Mayford et al., 1992), and that can produce a LTF of sensorimotor synapses in the intact abdominal ganglion (see Results). The 5-HT was then washed out and the 2:1 medium replaced by L15 culture medium, after which the ganglion was maintained in organ culture for $24 \mathrm{hr}$ at $17^{\circ} \mathrm{C}$. The next day the same motoneuron was reimpaled and voltage clamped at $-90 \mathrm{mV}$ in the presence of the $2: 1$ medium in order to obtain a second measurement of the HCA current (right). The area of the HCA current measured $24 \mathrm{hr}$ after 5-HT was significantly bigger than the control current. $C$, Current evoked in $\mathrm{I} .7$ by HCA on day 1 (left) and on day $2,24 \mathrm{hr}$ after a 90 min application By itself, anisomycin failed to significantly affect the current. $D$, After a control recording on day 1 (left), an application of anisomycin (20 $\mu \mathrm{M}$ ) was performed $30 \mathrm{~min}$ before and during the hour of 5-HT application. This blocked all increase in the HCA current measured on day 2 (right).

right pleuro-abdominal connective showed only a $20.3 \% \pm 26.3 \%$ decrease $(n=4 ; t=1.1, \mathrm{NS})$, while the $\mathrm{Cl}^{-}$-mediated synaptic current evoked in buccal neurons B3 or B6 by an action potential in cholinergic neurons B4 or B5 showed a mean decrease of $61.4 \% \pm 5.4(n=4 ; t=4.1, p<0.005)$.

For the HCA current to be an appropriate assay of functional synaptic receptors, it would also be preferable to show that the HCA current is mediated by nonsomatic receptors. This was done by comparing the HCA current measured in neuron L7 both before and after acute isolation of the soma (see figure of the protein synthesis inhibitor anisomycin (ANISO; $20 \mu \mathrm{M})(r i g h t)$. 
legend for procedure). This procedure was successful in four experiments. We found that an HCA current was almost nonexistent in the isolated soma (Fig. 2C,D). It was on average decreased by $88.3 \pm 7.1 \%$ relative to control. The holding current was also smaller $(-43.1 \pm 18.9 \%)$ in the isolated soma, as expected if a portion of the processes were under voltage clamp in the intact ganglion. The isolated soma was healthy in these experiments as shown by the normal characteristics of the spontaneously generated action potentials in these cells (Fig. $2 E$ ).

Long-term enhancement of the agonist response by 5-IIT

In an attempt to determine whether LTF in Aplysia is accompanied by a modification in the number of functional postsynaptic CNQX-sensitive receptors, the HCA current was measured in a control period and again $24 \mathrm{hr}$ following application of the modulatory transmitter 5-HT. This treatment should produce changes in the isolated ganglion similar to those induced during behavioral training for long-term sensitization. In experiments without the 5-HT treatment, the HCA current decreased by $10.7 \pm 7.8 \%$, showing that the response was fairly stable over a $24 \mathrm{hr}$ period in organ culture ( $n=8$; Figs. $3 A, 4)$. In contrast, in experiments where the abdominal ganglion was exposed to 5-HT, a significant increase of $60.4 \pm 11.9 \%$ was obtained ( $n=9$; Figs. $3 B, 4$ ) (see ANOVA below). The small change in holding current from day 1 to day 2 in control experiments was not significantly different from that observed in the $5-\mathrm{H}^{\prime} \mathrm{l}$ condition $(-11.1 \pm 7.1 \%$ and $+12.1 \pm 8.1 \%$, respectively; $t=2.1$, NS).

If this upregulation of EAA receptors is involved in LTF, it should likewise be blocked by inhibition of protein synthesis during the exposure to 5-HT (Montarolo et al,, 1986). Application of anisomycin by itself for $90 \mathrm{~min}$ failed to induce a significant change in the HCA current over a $24 \mathrm{hr}$ period (increase of $0.9 \pm 8.1 \% ; n=5$; Figs. $3 C, 4$ ). We found, however, that exposure of the abdominal ganglion to $20 \mu \mathrm{M}$ anisomycin 30 min before 5-HT as well as during 5-HT exposure completely blocked the long-term enhancement of the HCA current (average decrease of $12.5 \pm 19.2 \% ; n=5$; Figs. $3 D, 4$ ) (see ANOVA below). These results suggest that, as is the case for LTF, a protein-synthesis-dependent step is involved in the 5-HT-induced long-term enhancement of the HCA current.

Because anisomycin is a membrane-permeable inhibitor, bath application equally affects motoneurons and their presynaptic partners, i.e., sensory neurons and interneurons. Therefore, in the experiments described above, it was not clear whether the postsynaptic change was directly dependent on new protein synthesis in the motoneuron itself or whether it was indirectly dependent on new protein synthesis at the presynaptic level. In order to address this question more directly, we used a protein synthesis inhibitor that is membrane impermeant and could be directly injected in motoneuron L7. The plant-derived, eukaryotic ribosome-inactivating glycoprotein gelonin possesses such characteristics (Stripe et al., 1980; Falasca et al., 1982; Singh et al., 1989). Injected into Aplysia neurons, this inhibitor is effective at blocking protein synthesis (see Materials and Methods). Motoneurons L7 were preinjected with gelonin $1 \mathrm{hr}$ before application of 5-HT. As was found with the anisomycin pretreatment, gelonin-injected neurons failed to show a long-term increase in the HCA current. The average change over $24 \mathrm{hr}$ was a decrease of $21.5 \pm 4.4 \%(n=6$; Fig. 4). Gelonin-injected motoneurons not exposed to 5-HT also failed to show any significant change in their response to the EAA agonist HCA $(-8.5$

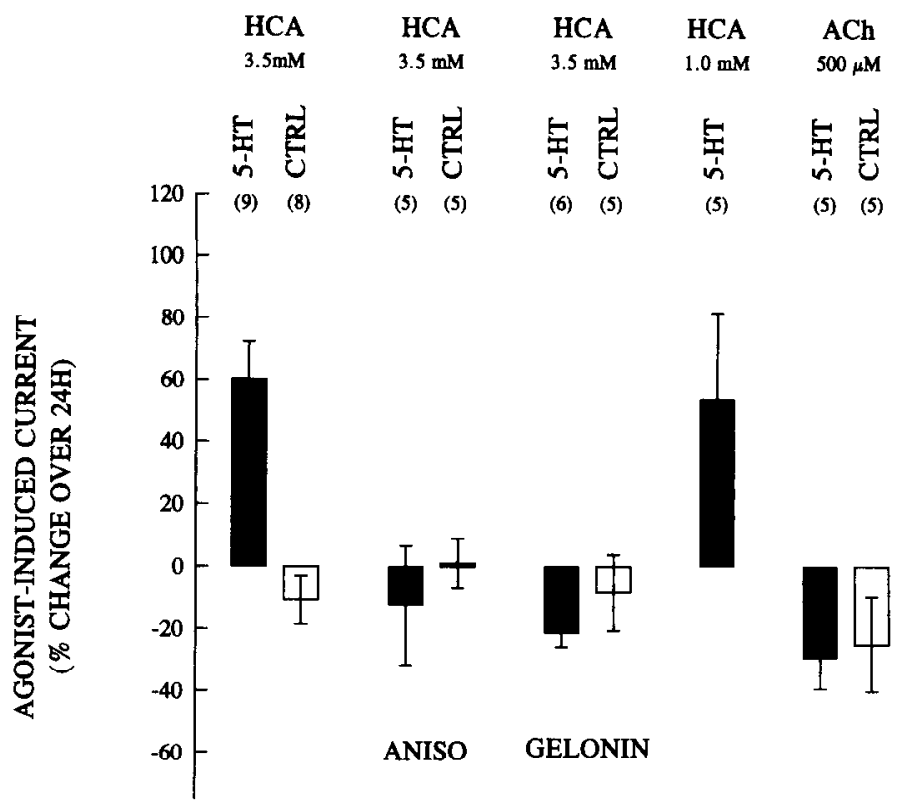

Figure 4. Summary of experiments on the long-term enhancement of the HCA current by 5-HT. The change in the area of currents evoked by HCA on 2 consecutive days is expressed as a percent score (day2/ day1). Error bars represent the standard error of the mean. The pretreatment (if any) is indicated at the bottom [anisomycin (ANISO) or GELONIN]. The treatment [5-HT or control (CTRL)] and agonist used (3.5 $\mathrm{mM} H C A, 1 \mathrm{mM} H C A$ or $500 \mu \mathrm{M}$ acetylcholine $(A C h)]$ are indicated above the graph. Both anisomycin and the gelonin injections were effective at blocking the long-term increase in the HCA current induced by 5 -HT. Similar increases in the HCA current by 5 -HT were obtained if the agonist $(H C A)$ was used at 1 or $3.5 \mathrm{~mm}$. Currents evoked by $\mathrm{ACh}$ were unaffected by the 5-HT treatment.

$\pm 12.2 \% ; n=5$; Fig. 4 ). These results suggest that the enhancement is specifically dependent on new protein synthesis in the postsynaptic cell. The results of the experiments described above were analyzed with a two-way ANOVA. The first factor was the treatment (control vs. 5-HT), while the second was pretreatment (control vs. anisomycin vs. gelonin). A significant effect of the pretreatment factor was detected $[F(2,32)=7.53, p<0.003]$ as well as a significant interaction between the two factors $[F(2,32)$ $=10.25, p<0.0004$ ]. A post hoc test [least significant difference (LSD)] confirmed that only in the preparations not exposed to the protein synthesis inhibitors was the effect of 5-HT significant $(p<0.0002)$.

Although the results obtained with the inhibitors of protein synthesis are compatible with the hypothesis that the enhancement in the response is due to an increase in the number of functional receptors, other explanations are also possible. For example, the effect could be the result of a protein-synthesisdependent increase in the affinity of the receptors for the agonist. We addressed this issue by activating the postsynaptic receptors with a concentration of HCA that is lower on the dose-response curve (see Fig. 1 $B$ ). If an increase in affinity was involved, a greater percent increase in the HCA current following 5-HT should be obtained. Using the agonist at a concentration of 1 mM instead of $3.5 \mathrm{~mm}$, we failed to obtain a greater increase in the HCA current. The average increase in these experiments 24 hr following the 5-HT treatment was $54.0 \pm 28 \%(n=5$; Fig. 4). This was not significantly different from the increase obtained with the agonist used at $3.5 \mathrm{~mm}(t=0.25$, NS).

In order to verify the specificity of the long-term increase in 
A

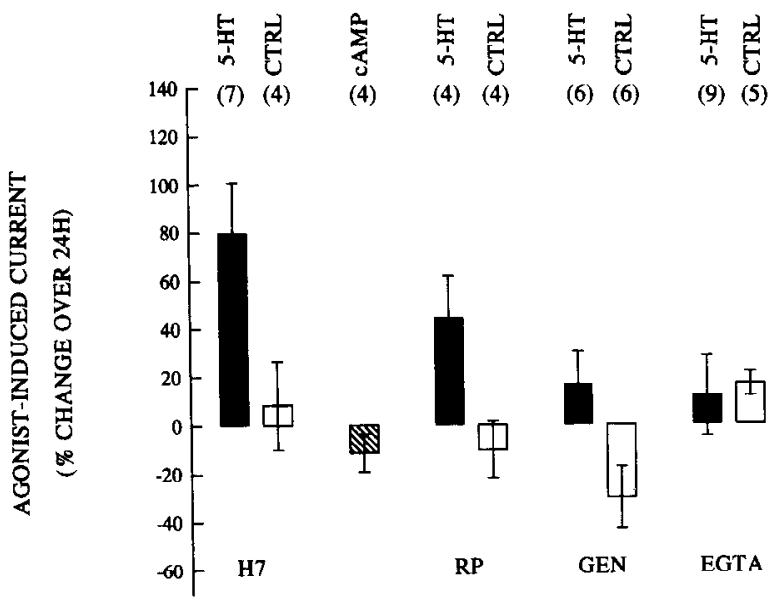

B

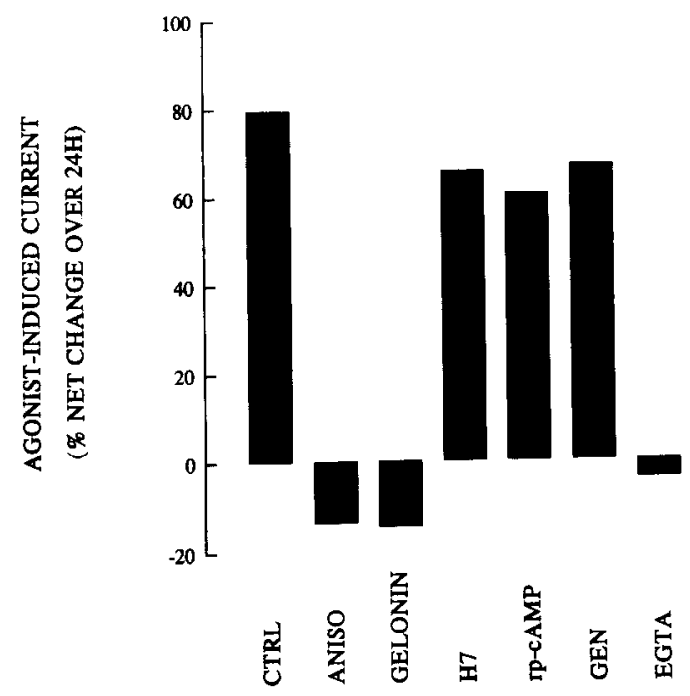

Figure 5. Summary of experiments on second-messenger systems involved in the long-term enhancement of the HCA current induced by 5-HT. $A$, The change in the area of currents evoked by HCA on 2 consecutive days is expressed as a percentage score (day2/day1). Error bars represent the standard error of the mean. The pretreatment (if any) is indicatcd at the bottom [H7 or Rp-cAMP $(R P)$ or genistein $(G E N)$ or $E G T A$ ]. The treatment [5-HT or Ctrl or cpt-cAMP (CAMP)] is indicated above the graph. The PKC inhibitor $\mathrm{H} 7(200 \mu \mathrm{M})$ applied 30 min before 5-HT and during the $60 \mathrm{~min}$ of $5-\mathrm{HT}$ was ineffective at blocking the long-term increase in the HCA current. Application of cptcAMP $(100 \mu \mathrm{M})$ on day 1 for $90 \mathrm{~min}$ in the presence of $500 \mu \mathrm{M}$ IBMX was without effect on the HCA current measured on day 2 . The tyrosine kinase blocker genistein applied at $20 \mu \mathrm{M} 30 \mathrm{~min}$ before 5-HT, during the 5-HT, and throughout the $24 \mathrm{hr}$ incubation failed to block the longterm enhancement of the HCA response. By itself, genistein induced a moderate decrease in the current over $24 \mathrm{hr}$. Preinjection of EGTA in the motoneuron before the 5-HT treatment was effective at blocking the enhancement. $B$, Summary of experiments on the effect of inhibitors on the long-term enhancement of the HCA current induced by 5-HT. The height of the bars represent the ratio of the mean percent scores of control preparations and 5-HT-treated preparations for each pretreatment conditions. For example, for the genistein condition, the ratio is $116.8 / 69.7$, for a net increase of $67.6 \%$.

the EAA response of motoneuron $\mathrm{L} 7$, the effect of 5-HT exposure on currents activated by acetylcholine $(\mathrm{ACh})$ in the same cell were also evaluated. ACh activates $d$-tubocurarine-sensitive receptors in motoneuron L7 (Wachtel and Kandel, 1967). The neuron was voltage clamped and exposed to 5-HT as above, but $\mathrm{ACh}(500 \mu \mathrm{M})$ was used as the agonist instead of HCA. Unlike the HCA current, the ACh current showed no increase $24 \mathrm{hr}$ aftcr the application of 5-H'T. The average change was a decrease of $29.4 \pm 10.1 \%(n=5$; Fig. 4). A similar decrease in the ACh current was seen in control preparations that were not exposed to 5 -HT $(-25.0 \pm 15.3 \% ; n=5$; Fig. 4). The two groups were not statistically different $(t=0.24$, NS). These results suggest that the long-term increase in the HCA current is not the result of generalized, nonspecific, postsynaptic modifications.

\section{Role of second messenger pathways}

To begin exploring the second messenger pathways that might be involved in the induction of the long-term enhancement of the EAA response, a series of inhibitors were applied to the preparation before and during the exposure to 5-HT. The protein kinase inhibitor $\mathrm{H} 7$, which is effective at blocking some actions of protein kinase C (PKC) in Aplysia (Conn et al., 1989; Ghirardi et al., 1992), was ineffective at blocking the enhancement of the HCA current, when applied at $200 \mu \mathrm{M} 30 \mathrm{~min}$ before and during the 5-HT treatment. An average increase of $80.0 \pm$ $20.9 \%$ was obtained over $24 \mathrm{hr}(n=7$; Fig. $5 A)$. By itself, the inhibitor caused a small increase in the HCA current $(+8.3 \pm$ 18.3\%; $n=5$; Fig. 5A).

Because cAMP analogs have been shown to be effective at inducing presynaptic growth and LTF of sensorimotor synapses of Aplysia in culture (Schacher et al., 1988, 1993; Glanzman et al., 1990; Nazif et al., 1991), we tested the possibility that such a treatment could mimic the long-term effect of 5-HT on the HCA current. The cAMP analog chlorophenylthio-cAMP (100 $\mu \mathrm{M})$ together with the phosphodiesterase inhibitor IBMX (500 $\mu \mathrm{M}$ ) were applied for a continuous period of $90 \mathrm{~min}$ (as in Schacher et al., 1988). This treatment was found to be without effect on the HCA current measured 24 hr later $(-11.3 \pm 7.9 \% ; n=4$; Fig. 5A). As expected from such a result, preapplication of the competitive protein kinase A (PKA) inhibitor Rp-cAMP (500 $\mu \mathrm{M}) 30 \mathrm{~min}$ before and during the 5 -HT was unable to block the long-term enhancement of the HCA current. The average increase was $44.7 \pm 17.5 \%(n=4$; Fig. $5 \mathrm{~A})$. In the absence of the 5-HT treatment, application of Rp-cAMP for 90 min caused a small decrease in the HCA current $24 \mathrm{hr}$ later $(-10.2 \pm 11.8 \%$; $n=4$; Гig. 5A).

The involvement of nonreceptor tyrosine kinase dependent pathways was investigated by using the general inhibitor genistein $(20 \mu \mathrm{M})$. In order to test the implication of this pathway in the induction as well as in the maintenance of the long-term postsynaptic change, the inhibitor was applied $30 \mathrm{~min}$ before and during the 5-HT treatment as well as throughout the $24 \mathrm{hr}$ incubation period. This inhibitor appeared initially to be effective at blocking the 5-HT-induced enhancement. The average increase of the HCA current was only of $16.8 \pm 13.8 \%$ in genistein-treated motoneurons ( $n=6$; Fig. $5 A$ ). However, we also found that the genistein application by itself produced a clear decrease in the HCA current over the $24 \mathrm{hr}$ incubation period $(-30.3 \pm 12.9 \% ; n=6$; Fig. $5 A$ ). The 5 -HT-treated and control groups were again significantly different (see ANUVA below).

Finally, the involvement of $\mathrm{Ca}^{2+}$-dependent pathways was investigatcd using postsynaptic iontophorctic injections of EGTA in motoneuron L7. The concentration of EGTA in the injection pipette was $100 \mathrm{~mm}$ (in water) and a $40 \mathrm{~min}$ injection of -40 $\mathrm{nA}$ was used. This pretreatment was found to be effective at 
blocking the long-term increase in the HCA current produced by $5-\mathrm{HT}$. While in the injected cells exposed to $5-\mathrm{HT}$ the average change was $+12.0 \pm 16.7 \%(n=9)$, in control cells without 5 -HT application the average change was $+16.8 \pm 5.1 \%(n=$ 5; Fig. 5A). Although these experiments do not allow to pinpoint the involvement of a specific second messenger pathway, they nonetheless suggest that a $\mathrm{Ca}^{2+}$-dependent step is involved. The effects of the various inhibitors tested were analyzed using a two-way ANOVA. The first factor was pretreatment (control vs. H7 vs. Rp-cAMP vs. genistein vs. EGTA) while the second factor was the treatment (control vs. 5-HT). The overall effects of the pretreatment and treatment factors were significant $[F(3,38)$ $=3.2, p<0.05$, and $F(1,38)=11.8, p<0.002$, respectively). Post hoc analysis (LSD test) showed that the effect of 5-HT was significant in the presence of $\mathrm{H} 7(p<0.005)$ and genistein $(p$ $<0.05$ ), marginally significant in the presence of $\operatorname{Rp}$-cAMP $(p$ $=0.06)$, and not significant $(p>0.05)$ in the EGTA group.

Figure $5 B$ presents a summary of the experiments described above, but takes into account the effects of the inhibitors by themselves by computing the ratio of the experimental and control conditions in each series of experiments. For example, in the experiments using genistein, the net increase would be $67.6 \%$ ( $116.8 \%$ over $69.7 \%$ ).

\section{Role of agonist response enhancement in long-term synaptic facilitation}

Although our results show that a treatment that should induce LTF of sensorimotor synapses also induces a long-term increase in the response of the motoneuron to an agonist of the synaptic, receptors, it is not clear whether this effect is involved in or necessary for LTF. This was investigated by first verifying that the treatment used (60 min 5-HT) was, indeed, capable of inducing LTF under our conditions. We then tested whether LTF was altered under conditions where the long-term enhancement of the postsynaptic response was prevented by injection of gelonin in the motoneuron.

In these experiments, $\mathrm{L} 7$ was impaled by two electrodes and polarized to $-80 \mathrm{mV}$. A variable number of sensory neurons of the LE or rLE clusters were then consecutively impaled and stimulated in order to evoke an action potential and measure the amplitude of the EPSPs in L7. Upon impalement, a $3 \mathrm{~min}$ rest was imposed and then two EPSPs were recorded from each synapses with an interval of $2 \mathrm{~min}$. Only EPSPs with an amplitude greater than $1 \mathrm{mV}$ were accepted for analysis because these are less susceptible to errors of measurement. In some experiments, 75-100 $\mu \mathrm{M} d$-tubocurarine was added to the bath in order to block spontaneous cholinergic synaptic potentials that interfered with the measurement of sensorimotor EPSPs. This treatment does not affect sensorimotor transmission or the effects of 5-HT (Trudeau and Castellucci, 1993b). The position of each of the sensory neurons was precisely mapped so that they could be reidentified with certainty the next day. Only sensory neurons that could be precisely located on the basis of their proximity to other large neurons and on the basis of their distinctive orange pigmentation were used in these experiments. The two EPSPs were averaged and compared to the average of two EPSPs measured at the same synapse $24 \mathrm{hr}$ following application of 5-HT ( $5 \mu \mathrm{M}, 60 \mathrm{~min})$. The percent change obtained for all synapses tested in a given ganglion were averaged and contributed one score. This treatment was effective at producing a LTF of the sensorimotor synapses. While control, untreated synapses underwent a small decrease of $12.8 \pm 11.9 \%(n=6$;
DAY 1

DAY 2

A

CTRL

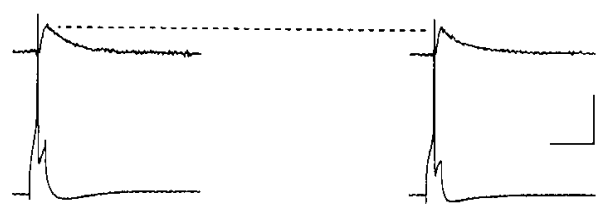

B

5-HT

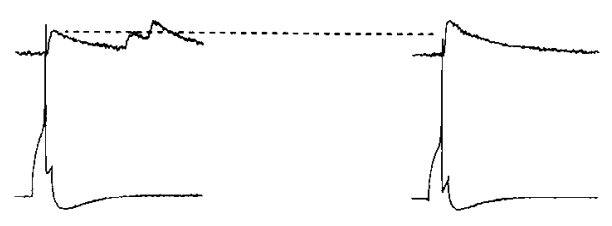

C

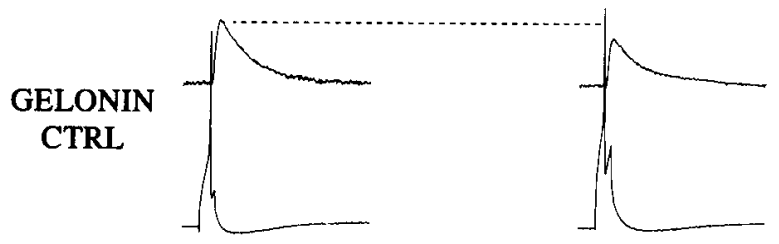

D

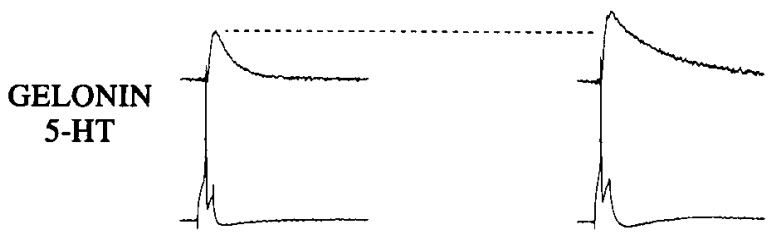

E

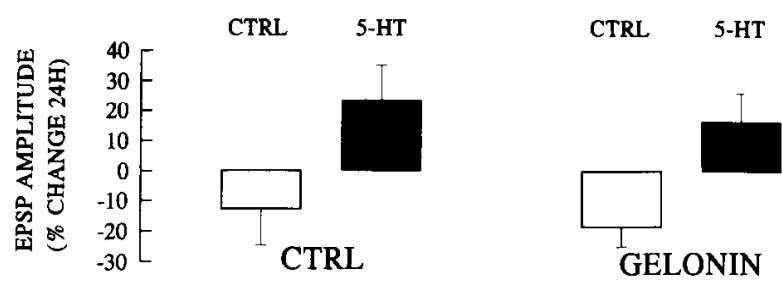

Figure 6. Effect of postsynaptic gelonin injections on long-term synaptic facilitation of sensorimotor connections. $A$, Individually identified sensory neurons were impaled on 2 consecutive days and the amplitude of the EPSPs (upper traces) that they evoked in motoneuron L7 following an action potential (lower traces) was measured. Two EPSPs were evoked (interval $2 \mathrm{~min}$ ) and averaged on day 1 and day 2. In control (CTRL) experiments, the EPSPs were stable over $24 \mathrm{hr}$, showing only a small decrease. Calibration: $4 \mathrm{mV}, 25 \mathrm{mV}, 125 \mathrm{msec}$ (calibration also applies to $B-D)$. $B$, Application of $5-\mathrm{HT}(5 \mu \mathrm{M})$ for $60 \mathrm{~min}$ on day 1 following the control EPSPs induced an increase in the amplitude of EPSPs evoked at the same synapse $24 \mathrm{hr}$ later. The additional EPSPs on the left trace are of spontaneous origin. $C$, After measurement of the control EPSPs on day 1 , the ribosome-inactivating toxin gelonin was injected in motoneuron L7. The EPSPs measured at the same synapses $24 \mathrm{hr}$ later were slightly decreased. $D$, After measurement of control EPSPs on day 1 , the motoneuron was injected with gelonin. After a 60 min delay 5-HT $(5 \mu \mathrm{M})$ was applied for $60 \mathrm{~min}$. The EPSPs measured at the same synapses $24 \mathrm{hr}$ later were significantly increased relative to day $1 . E$, Summary of the experiments on long-term synaptic facilitation. The bars represent the percent change in the amplitude of EPSPs from day 1 to day 2 . The error bars represent the standard error of the mean. The pretreatment (CONTROL vs. GELONIN) is indicated below the bars. The treatment [control $(C T R L)$ or $5-H T$ ] is indicated above the bars. The neuromodulator 5-HT induced an overall significant facilitation of these synapses lasting $24 \mathrm{hr}$. 'This was not prevented by blocking protein synthesis in the postsynaptic neuron with an injection of gelonin. 
15 synapses, Fig. $6 A$ ), the 5 -HT-treated synapses showed on average an increase of $23.4 \pm 11.5 \%(n=6 ; 12$ synapses, Fig. $6 B$ ). In another series of experiments, the measurement of the control EPSPs the first day was followed by an injection of gelonin in the motoneuron. The preparation was then exposed to 5 -HT $60 \mathrm{~min}$ after the injection. We found that in geloninpretreated motoneurons, LTF was still produced. In preparations where motoneurons were pretreated with gelonin but unexposed to 5-HT, a small decrease in the amplitude of EPSPs was obtained $(-18.5 \pm 6.5 \% ; n=6 ; 13$ synapses, Fig. $6 C$ ). However, in 5-HT-treated synapses, an increase of $16.4 \pm 9.6 \%$ was obtained $24 \mathrm{hr}$ after the treatment ( $n=6 ; 18$ synapses, Fig. $6 D$ ). A summary of these results is presented in Figure $6 E$. The data were analyzed with a two-way ANOVA, the first factor being the pretreatment (Ctrl vs. gelonin), the second being the treatment (Ctrl vs. 5-HT). This analysis confirmed that overall, the 5 -HT treatment produced a significant facilitation $[F(1,20)=$ $12.5, p<0.005)$. No significant interaction with the pretreatment was obtained. These results suggest that the LTF obtained $24 \mathrm{hr}$ after the 5-HT treatment is not dependent on protcin synthesis in the postsynaptic neuron.

\section{Discussion}

Long-term facilitation (LTF) of sensorimotor synapses is one of the cellular mechanisms that is thought to underlie long-term sensitization of withdrawal reflexes in Aplysia (Pinsker et al., 1973; Frost et al., 1985). Although much effort has been directed at understanding the presynaptic mechanisms implicated, most notably the growth of new synaptic terminals (Bailey and Chen, 1983; Glanzman et al., 1990; Schacher et al., 1993), little is known about the postsynaptic reorganization that should accompany the establishment of these new synaptic connections. The recent pharmacological characterization of the receptors present at these synapses (Trudeau and Castellucci, 1993a; Dale and Kandel, 1993) has allowed us to test the hypothesis that LTF could be accompanied by an increase in the number of functional CNQX-sensitive EAA receptors on motoneurons that mediate the gill and siphon withdrawal (GSW) reflex.

We found that homocysteic acid (HCA) could be used as an effective agonist of the synaptic receptors. Like the synaptic receptors, the receptors activated by $\mathrm{HCA}$ are (1) sensitive to the antagonist CNQX (Fig. $1 C, D$ ), (2) particularly sensitive to digestion with bacterial protease (Fig. $2 A, B$ ), and (3) have a nonsomatic localization (Fig. $2 C, D$ ).

A 60 min application of the neuromodulator 5-HT is able to induce an increase in the HCA current lasting $24 \mathrm{hr}$ (Figs. 3, 4). Under the same conditions, we verified that LTF of sensorimotor synapses was indeed established (Fig. 6). The long-lasting enhancement of the response to the agonist was found to depend on new protein synthesis, and specifically on postsynaptic protein synthesis (Figs. 3,4). Although compatible with the hypothesis of an upregulation of postsynaptic receptor synthesis, our results cannot exclude the possibility that the effect, although protein-synthesis dependent, may be the result of a posttranslational activation of previously existing but nonfunctional receptors. Two other mechanisms could be involved but are less likely. These would implicate a stable number of functional receptors but with a change either in the affinity of the receptor for the agonist or in the conductance associated with receptor activation. These possibilities are less likely for two reasons. First, a quantal analysis of I.TF has previously failed to find any change in the characteristics of spontaneous miniature ex- citatory postsynaptic potentials (mEPSPs) recorded in the motoneuron (Dale et al., 1988). An increase in receptor affinity or conductance would have been likely to be detected as an increase in the size of mEPSPs. Second, although this is only indirect evidence, we find the same enhancement of the HCA current using a lower concentration of the agonist that should be more sensitive to a change in receptor affinity (Fig. 4).

Our experiments investigating the involvement of secondmessenger cascades in the establishment of the postsynaptic change have not allowed us to confirm the implication of a specific pathway, although changes in postsynaptic $\mathrm{Ca}^{2+}$ could be involved because injections of EGTA into the postsynaptic neuron can block the effect (Fig. 5A). Future experiments should investigate the role of $\mathrm{Ca}^{2+}$-dependent pathways such as those involving the $\mathrm{Ca}^{2+} /$ calmodulin-dependent kinase or nitric oxide synthase. It also remains to be determined whether the postsynaptic change in the response to the agonist is induced directly by $5-\mathrm{HT}$ activating receptors on the motoneuron itself. Another possibility is that the effect is indirectly mediated by 5-HTevoked presynaptic changes. One could hypothesize that the postsynaptic change occurs only in response to the initial presynaptic growth, perhaps through changes in signaling mediated by cell-adhesion molecules. Recent work suggests that diverse second-messenger cascades can, indeed, be activated through this type of interaction (Von Bohlen Und Halbach et al., 1992; Williams et al., 1992). Interestingly, it has been reported recently that a 60 min exposure to 5-HT can induce changes in the levels of a neural cell adhesion molecule (NCAM)-related protein on the surface of sensory neurons (Mayford et al., 1992), although the relationship of this phenomenon to LTF has not been established. Our finding that a treatment that has been previously shown to induce presynaptic growth (cpt-cAMP + IBMX; Schacher et al., 1988) failed to mimic the effect of 5-HT on the enhancement of the HCA current (Fig. 5A), however, argues against the hypothesis that the postsynaptic change occurs in response to the presynaptic growth. It should be noted, however, that the previous report used synapses formed in culture. It is possible that the same treatment is ineffective at inducing the presynaptic growth in the whole abdominal ganglion under our conditions perhaps simply because of less effective diffusion in the tissue. On the other hand, it is known that an intracellular injection of cAMP in sensory neurons can induce growth in the intact pleural ganglion (Nazif et al., 1991).

Although our results provide evidence for postsynaptic changes that parallel LTF, the enhanced responsiveness of postsynaptic EAA receptors does not appear to be necessary for LTF measured $24 \mathrm{hr}$ following the 5-HT exposure (Fig. 6). This shows at the same time that postsynaptic protein synthesis is not necessary for the LTF measured at a $24 \mathrm{hr}$ time point because the facilitation still occurs in gelonin-injected motoneurons. In the context of the present model of LTF, which implicates the growth of new synaptic terminals as supporting the expression of this form of plasticity, our results suggest that the initial stages of the facilitation (up to $24 \mathrm{hr}$ ) are supported by presynaptic growth associated with the redistribution of a reserve pool of postsynaptic receptors to the new sites of contact. Later stages of LTF may require an increased synthesis of receptors that may function to replenish the reserve pool and may be necessary for the maintenance of LTF for periods longer than $24 \mathrm{hr}$. For example, it would be interesting to verify whether $48 \mathrm{hr}$ LTF can be attenuated by a postsynaptic injection of gelonin. As suggested by Bailey and Chen (1989), LTF may, indeed, be expressed 
through a sequence of different stages over a time course of days to weeks.

Although the upregulation of EAA receptors does not appear to be necessary for the $24 \mathrm{hr}$ facilitation of sensorimotor synapses, it is possible that this effect reflects a postsynaptic modification involved in long-term facilitation of other synapses impinging on $\mathrm{L} 7$ such as excitatory interneuronal synapses, which we have also demonstrated to be CNQX-sensitive (Trudeau and Castellucci, 1993a). Long-term facilitation of these synapses has yet to be demonstrated. An additional issue that we have not yet addressed is whether 5-HT also induces a short-term upregulation of postsynaptic receptors.

Other recently published data may also be interpreted as providing support for coordinate pre- and postsynaptic changes during LTF. It has been found that 5-HT was more effective at producing LTF when it was applied both to the soma of sensory neurons and to the region including synaptic terminals and postsynaptic neurons (Clark and Kandel, 1993; Emptage and Carew, 1993). Although these data have been interpreted as suggesting that a signal was sent from the terminals to the soma of the sensory neurons, another interpretation is that a postsynaptic action of 5-HT enhances the LTF associated with the presynaptic growth, perhaps initially by promoting the recruitment of receptors to the new sites of contact. Although it is possible that optimal induction of LTF requires 5-HT reaching the postsynaptic neuron, the results of these two studies, nonetheless, show that LTF can be obtained under conditions where 5-HT docs not reach the motoneuron.

In order to further investigate the possibility that LTF is associated with an increase in the number of functional postsynaptic receptors, a more direct approach will be necessary. We have recently obtained preliminary data showing that a specific ${ }^{3} \mathrm{H}$-kainate binding site is present in Aplysia neuronal membranes (J. Bernard, L.-E. Trudeau, G. Massicotte, and V. F. Castellucci, unpublished observations). This binding can be displaced by CNQX or kainate and could, therefore, be used as an assay for determining the number and affinity of postsynaptic receptors.

In conclusion, we suggest that LTF is accompanied by a protein synthesis-dependent upregulation of postsynaptic EAA receptors. Our data are compatible with this effect being mediated by an increase in the number of functional receptors. We also conclude that LTF measured at a $24 \mathrm{hr}$ time point does not require postsynaptic protein synthesis. The postsynaptic upregulation of EAA receptors may become necessary for stages of LTF lasting more than $24 \mathrm{hr}$ and may also prime the postsynaptic neuron for subsequent learning-associated plasticity by increasing the number of receptors available in a reserve pool.

\section{References}

Agranoff BW, Klinger PD (1964) Puromycin effect on memory in the goldfish. Science 146:952-953.

Alberini CM, Ghirardi M, Metz R, Kandel ER (1994) C/EBP is an immediate-early gene required for the consolidation of long-term facilitation in Aplysia. Cell 76:1099-1114.

Bailey $\mathrm{CH}$, Chen M (1983) Morphological basis of long-term habituation and sensitization in Aplysia. Science 220:91-93.

Bailey CH, Chen M (1988a) Long-term memory in Aplysia modulates the total number of varicosities of single identified sensory neurons. Proc Natl Acad Sci USA 85:2373-2377.

Bailey CH, Chen M (1988b) Long-term sensitization in Aplysia increases the number of presynaptic contacts onto the identified gill motor neuron L7. Proc Natl Acad Sci USA 85:9356-9359.

Bailey $\mathrm{CH}$, Chen M (1989) Time course of structural changes at iden- tified sensory neuron synapses during long-term sensitization in Aplysia. J Neurosci 9:1774-1780.

Bailey CH, Montarolo P, Chen M, Kandel ER, Schacher S (1992) Inhibitors of protein and RNA synthesis block structural changes that accompany long-term heterosynaptic plasticity in Aplysia. Neuron 9:749-758.

Barondes SH, Cohen HD (1967) Delayed and sustained effect of acetoxycycloheximide on memory in mice. Proc Natl Acad Sci USA 58 157-164.

Barondes SH, Cohen HD (1968) Memory impairment after subcutaneous injection of acetoxycycloheximide. Science 160:556-557.

Barzilai A, Kennedy TE, Sweatt JD, Kandel ER (1989) 5-HT modulates protein synthesis and the expression of specific proteins during long-term facilitation in Aplysia sensory neurons. Neuron 2:15771586 .

Bcrgold PJ, Bcushausen SA, Sacktor TC, Cheley S, Bayley H, Schwartz JH (1992) A regulatory subunit of the cAMP-dependent protein kinase down-regulated in Aplysia sensory neurons during long-term sensitization. Neuron 8:387-397.

Broadie K, Bates M (1993) Innervation directs receptor synthesis and localization in Drosophila embryo synaptogenesis. Nature 361:350353.

Caroni P, Rotzler S, Britt JC, Brenner HR (1993) Calcium influx and protein phosphorylation mediate the metabolic stabilization of synaptic acetylcholine receptors in muscle. J Neurosci 13:1315-1325.

Castellucci VF, Kennedy TE, Kandel ER, Goelet P (1988) A quantitative analysis of 2-D gels identifies proteins whose labeling is increased following long-term sensitization in Aplysia. Neuron 1:321328.

Castcllucci VF, Blumenfcld H, Goclet P, Kandel ER (1989) Inhibitor of protein synthesis blocks long-term behavioral sensitization in the isolated gill-withdrawal reflex of Aplysia. J Neurobiol 20:1-9.

Clark GA, Kandel ER (1993) Induction of long-term facilitation in Aplysia sensory neurons by local application of serotonin to remote synapses. Proc Natl Acad Sci USA 90:11411-11415.

Conn PJ, Strong JA, Azhderian EM, Nairn AC, Greengard P, Kaczmarek LK (1989) Protein kinase inhibitors selectively block phorbol ester- or forskolin-induced changes in excitability of Aplysia neurons. J Neurosci 9:473-479.

Crow T, Forrester J (1990) Inhibition of protein synthesis blocks longterm enhancement of generator potentials produced by one-trial in vivo conditioning in Hermissenda. Proc Natl Acad Sci USA 87:44904494.

Dale N, Kandel ER (1993) L-Glutamate may be the fast cxcitatory transmitter of Aplysia sensory neurons. Proc Natl Acad Sci USA 90: $7163-7167$

Dale N, Kandel ER, Schacher S (1987) Serotonin produces long-term changes in the excitability of Aplysia sensory neurons in culture that depends on new protein synthesis. J Neurosci 7:2232-2238.

Dale N, Schacher S, Kandel ER (1988) Long-term facilitation in Aplysia involves increase in transmitter release. Science 239:282-285.

Dash PK, Hochner B, Kandel ER (1990) Injection of the cAMPresponsive element into the nucleus of Aplysia sensory neurons blocks long-term facilitation. Nature 345:718-721.

Deadwyler SA, Dunwiddie T, Lynch G (1987) A critical level of protein synthesis is required for long-term potentiation. Synapse 1:9095.

Dubuc B, Castellucci VF (1991) Receptive fields and properties of a new cluster of mechanoreceptor neurons innervating the mantle region and the branchial cavity of the marine mollusk Aplysia californica. J Exp Biol 156:315-334.

Emptage NJ, Carew TJ (1993) Long-term synaptic facilitation in the absence of short-term facilitation in Aplysia neurons. Science 262 253-256.

Eskin A, Garcia KS, Byrne JH (1989) Information storage in the nervous system of Aplysia: specific proteins affected by scrotonin and cAMP. Proc Natl Acad Sci USA 86:2458-2462.

Falasca A, Gasperi-Campani A, Abbondanza A, Barbieri L, Stripe F (1982) Properties of the ribosome-inactivating proteins gelonin, momordica charantia, and dianthins. Biochem J 207:505-509.

Flexner JB, Flexner LB, Stellar E (1963) Memory in mice as affected by intracerebral puromycin. Nature 141:57-59.

Froehner SC (1993) Regulation of ion channel distribution at synapses Ann Rev Neurosci 16:347-368.

Frost WN, Castellucci VF, Hawkins RD, Kandel ER (1985) Mono- 
synaptic connections made by the sensory neurons of the gill- and siphon-withdrawal reflex in Aplysia participate in the storage of longterm memory for sensitization. Proc Natl Acad Sci USA 82:82668269.

Ghirardi M, Braha O, Hochner B, Montarolo PG, Kandel ER (1992) Roles of PKA and PKC in facilitation of evoked and spontaneous transmitter release at depressed and nondepressed synapses in Aplysia sensory neurons. Neuron 9:479-489.

Glanzman DL, Kandel ER, SchacherS (1990) Target-dependent structural changes accompanying long-term synaptic facilitation in Aplysia neurons. Science 249:799-802.

Grecksch G, Matthies H (1980) Two sensitive periods for the amnesic effect of anisomycin. Pharmacol Biochem Behav 12:663-665.

Greenberg SM, Castellucci VF, Bayley H, Schwartz JH (1987) A molecular mechanisms for long-term sensitization in Aplysia. Nature 329:62-65.

Horn G, McCabe BJ, Bateson PPG (1979) An autoradiographic study of the chick brain after imprinting. Brain Res 168:361-373.

Hu Y, Barzilai A, Chen M, Bailey CH, Kandel ER (1993) 5-HT and cAMP induce the formation of coated pits and vesicles and increase the expression of clathrin light chain in sensory neurons of Aplysia. Neuron 10:921-929.

Kaang B-K, Kandel ER, Grant SGN (1993) Activation of cAMPresponsive genes by stimuli that produce long-term facilitation in Aplysia sensory neurons. Neuron 10:427-435.

Kennedy TE, Kuhl D, Barzilai A, Sweatt JD, Kandel ER (1992) Longterm sensitization training in Aplysia leads to an increase in calreticulin, a major presynaptic calcium-binding protein. Neuron 9:10131024.

Kimura N, Kurosawa N, Kondo K, Tsukada $Y$ (1993) Molecular cloning of the kainate-binding protein and calmodulin genes which are induced by an imprinting stimulus in ducklings. Mol Brain Res 17:351-355.

Krug M, Lossner B, Ott T (1984) Anisomycin blocks the late phase of long-term potentiation in the dentate gyrus of freely moving rats. Brain Res Bull 13:39-42.

Kuhl D, Kennedy TE, Barzilai A, Kandel ER (1992) Long-term sensitization training in Aplysia leads to an increase in the expression of $\mathrm{BiP}$, the major protein chaperon of the ER. J Cell Biol 119:10691075.

Mayford M, Barzilai A, Keller F, Schacher S, Kandel ER (1992) Modulation of an NCAM-related adhesion molecule with long-term synaptic plasticity in Aplysia. Science 256:638-644.

Montarolo PG, Goelet P, Castellucci VF, Morgan J, Kandel ER, Schacher S (1986) A critical period for macromolecular synthesis in longterm heterosynaptic facilitation in Aplysia. Science 234:1249-1254.

Montarolo PG, Kandel ER, Schacher S (1988) Long-term heterosynaptic inhibition in Aplysia. Nature 333:171-174.

Nazif FA, Byrne JH, Cleary LJ (1991) cAMP induces long-term morphological changes in sensory neurons of Aplysia. Brain Res 539:324327 .

Noel F, Scholtz KP, Eskin A, Byrne JH (1991) Common set of proteins in Aplysia sensory neurons affected by an in vitro analogue of longterm sensitization training, 5-HT and cAMP. Brain Res 568:67-75.

Noel F, Nunez-Regueiro M, Cook R, Byrne JII, Eskin A (1993) Longterm changes in synthesis of intermediate filament protein, actin and other proteins in pleural sensory neurons of Aplysia produced by an in vitro analogue of sensitization training. Mol Brain Res 19:203-210.
Pinsker HM, Hening WA, Carew TJ, Kandel ER (1973) Long-term sensitization of a defensive withdrawal reflex in Aplysia. Science 182 1039-1042.

Schacher S, Montarolo PG (1991) Target-dependent structural changes in sensory neurons of Aplysia accompany long-term heterosynaptic inhibition. Neuron 6:679-690.

Schacher S, Castellucci VF, Kandel ER (1988) cAMP evokes longterm facilitation in Aplysia sensory neurons that requires new protein synthesis. Science 240:1667-1669.

Schacher S, Kandel ER, Montarolo PG (1993) cAMP and arachidonic acid simulate long-term structural and functional changes produced by neurotransmitters in Aplysia sensory neurons. Neuron 10:1079_ 1088.

Scholz KP, Byrne JH (1987) Long-term sensitization in Aplysia: biophysical correlates in tail sensory neurons. Science 233:685-687.

Scholz KP, Byrne JH (1988) Intracellular injection of cAMP induces a long-term reduction of neuronal $\mathrm{K}^{+}$currents. Science 240:1664 1666.

Schwartz JH, Swanson ME (1987) Dissection of tissues for characterizing nucleic acids from Aplysia: isolation of the structural gene encoding calmodulin. Methods Enzymol 139:277-290.

Singh V, Sairam MR, Bhargavi GN, Akhras RS (1989) Hormonotoxins: preparation and characterization of ovine luteinizing hormone-gelonin conjugate. J Biol Chem 264:3089-3095.

Stripe F, Olsnes S, Pihl A (1980) Gelonin, a new inhibitor of protein synthesis, nontoxic to intact cells. J Biol Chem 255:6947-6953.

Sweatt JD, Kandel ER (1989) Persistent and transcriptionally dependent increase in protein phosphorylation in long-term facilitation of Aplysia sensory neurons. Nature 339:51-54.

Takamatsu K, Tsukada Y (1985) Neurochemical studies on imprinting behavior in chick and duckling. Neurochem Res 10:1371-1390.

Trudeau L-E, Castellucci VF (1992) Contribution of polysynaptic pathways in the mediation and plasticity of Aplysia gill and siphon withdrawal reflex: evidence for differential modulation. J Neurosci $12: 3838-3848$.

Trudeau L-E, Castellucci VF (1993a) Excitatory amino acid neurotransmission at sensory-motor and interneuronal synapses of Aplysia californica. J Neurophysiol 70:1221-1230.

Trudeau L-E, Castellucci VF (1993b) Functional uncoupling of inhibitory interneurons plays an important role in short-term sensitization of Aplysia gill and siphon withdrawal reflex. J Neurosci 13: 2126-2135.

Von Bohlen Und Halbach F, Taylor J, Schachner M (1992) Cell type specific effects of the neural adhesion molecules L1 and NCAM on diverse second messenger systems. Eur J Neurosci 4:896-909.

Wachtel H, Kandel ER (1967) A direct synaptic connection mediating both excitation and inhibition. Science 158:1206-1208.

Williams E, Doherty P, Turner G, Reid RA, Hemperly JJ, Walsh FS (1992) Calcium influx can solely account for cell-contact dependent neurite outgrowth stimulated by transfected L1. J Cell Biol 119:883892.

Wittstock S, Kaatz HH, Menzel R (1993) Inhibition of brain protein synthesis by cycloheximide does not affect formation of long-term memory in honeybees after olfactory conditioning. J Neurosci 13: 1379-1386.

Wu F, Schacher S (1994) Pre- and postsynaptic changes mediated by two second messengers contribute to expression of Aplysia long-term heterosynaptic inhibition. Neuron 12:407-421. 